\title{
EDITORIAL
}

\section{The micropalaeontological record of global change}

It is a great pleasure to be introducing this set of four thematic papers, which arose from the symposium 'The Micropalaeontological Record of Global Change' at the Third International Palaeontological Congress (IPC3) last year (28 June-3 July, 2010). Co-hosted by the Natural History Museum and Imperial College, London, IPC3 was brought to the UK under the auspices of the Palaeontological Association, thanks to the efforts of many but most notably Prof. Dick Aldridge, who chaired the IPC3 organizing committee. With Dick's own strong micropalaeontological interests, and this unique opportunity for the UK's palaeontological societies to join together as hosts to such a major international event, The Micropalaeontology Society (TMS) gave IPC3 its whole-hearted support.

It is, perhaps, difficult to express the particular benefits and unique quality of a given scientific gathering; reports fill the pages of society newsletters, for repeat attendees at regular meetings their general feel becomes dissipated across halfremembered backgrounds of host institutions, cities and postconference outcrops. To me, IPC3 felt like something different. The idea of the International Palaeontological Congress in itself is a new initiative. I remember hearing of plans for IPC2 in Beijing during my PhD studies. There were murmurs of excitement through the palaeontological community and a totting up of costs amongst the research students. As a very junior micropalaeontologist with a palaeoceanographic bent, IPC2 was a curiosity, and I was happy enough to watch my vertebrate palaeontologist office-mate go with moderate interest but little envy. IPC3, however, was different. Here was the world-leading palaeontological gathering, right on our doorstep - for me, in my very institution.

IPC3, and specifically the TMS support of its organization and scientific programme, expressed a number of strengths, achievements and, dare I say it, creative tensions within the UK palaeontological community. First, it was an expression of the continuing growth of TMS as a mature learned society in the international arena. In the sponsorship of two IPC3 symposia 'The Micropalaeontological Record of Global Change' and 'Microfossil Contributions to Understanding the Tree of Life' the TMS made a significant contribution to the IPC3 scientific programme. I remember standing in the registration queue and overhearing a conversation between two North American delegates, who, while examining the programme for the week, commented on the presence of micropalaeontology. It may have been along the lines of 'vertebrates - yes; urchins, seashells and corals - yes; burrows and tracks - yes; theoretical evolutionarydevelopment - yes; molecular phlyogenetics - yes; cladistics yes; but micropalaeontology?', but the sheer number of micropalaeontologists, probably $10 \%$ or more of the conference's 850 delegates, meant that our presence could not be denied. There may be many reasons for such a perceived distance of micropalaeontology from the wider palaeontological community, not least the application and contribution of our discipline to other fields of research, notably global change science, and the large proportion of our community employed in the industrial sector. Many micropalaeontologists do have different interests and concerns to our macropalaeontological colleagues, but that should not preclude the scientific insight and added rigour that can be gained from regular exposure to each other's methods and data.

Related to the first, the second strength of the IPC3, was the collaboration and understanding between the host palaeontological societies. Perhaps the triple 'generational' relationship between the Geological Society, the Palaeontological Association and the TMS (or British Micropalaeontological Society as was) fosters a certain family understanding. Certainly, sharing committee members aids communication, as does a history of shared scientific gatherings, such as the Lyell meetings. IPC3 was, thus, an expression of the strength of both the Palaeontological Association and TMS on the international stage and an opportunity to again remind ourselves of common interests and concerns. As representatives of what might be, unflatteringly, termed the 'sub-discipline', it will require continued efforts by micropalaeontologists and TMS to maintain and expand our contribution to the science, teaching and community of palaeontology; meetings such as the IPC are one way of achieving this.

The four papers gathered together here represent just a small fraction of the 55 contributions submitted to the first of the TMS-sponsored IPC3 sessions, 'The Micropalaeontological Record of Global Change'. It has been very satisfying, however, to continue to engage with the authors concerned in the year since the IPC3 meeting and to see some aspects of their research presented here as papers. Their publication in the Journal of Micropalaeontology is particularly apt given the support of TMS throughout the organization of IPC 3 and this particular session. The stated aim of the symposium 'The Micropalaeontological Record of Global Change' was 'to present new micropalaeontological approaches to understanding interactions between the biosphere and past global environmental change'. In the event, the symposium did address some of the major questions on the evolution of life and the planet, from the interrelationships between biomineralization and ocean chemistry to our understanding of the biotic response to major environmental change. In just four papers, this themed set illustrates the potential breadth of micropalaeontological research in global change science. The contributions span some 400 million years of Earth history, shed light on the changing biosphere in both the marine and terrestrial realms and include microfossils/microremains produced by vertebrates, plants, amoebae and unicellular algae.

With this diverse range of contributions, for simplicity, the four papers have been ordered stratigraphically, from oldest to youngest. We thus begin in the Palaeozoic, with the overview provided by Žigaitè et al. (2011) of recent work on the microvertebrate record of Siberia and Central Asia. This is an interesting contribution to our understanding of microvertebrate remains in an area and stratigraphic interval where there is 
limited published literature available. Žigaitè et al. are clearly experienced in this region and with this material. They are thus able to draw upon collections, local field reports and their own sampling to summarize their understanding of the biogeography and stratigraphic distribution of the key microvertebrate taxa across these provinces. Not only is this a potential point of access for other researchers in this field, it also highlights the work undertaken, as well as the efforts still needed, in the taxonomic description and stratigraphic/geographical documentation of such faunas. This is important, as Žigaite et al. point out, for practical issues of Palaeozoic biostratigraphy but also in our understanding of continental reconstructions, biogeography and early vertebrate evolution.

The second paper, by Mander (2011), investigates our ability to link an observed pollen and spore record with the underlying terrestrial vegetation changes across the Triassic-Jurassic boundary in Greenland. Based on a large dataset, Mander investigates the taxonomic level at which the observed spores and pollens can be given a robust botanical affinity; in this case study only $50 \%$ of spores and pollen he records have a known botanical affinity at family level. Although based on a particular stratigraphic level, and the associated interval of global change, this investigation of the association between macro- and microfossil records of vegetation will be of interest to all palynologists working on terrestrial records. The problem of taxonomic imprecision identified by Mander is, however, more acute in such ancient plant communities.

The study of Friedrich et al. (2011) takes us into the marine realm, with a reconstruction of bottom-water oxygenation variability through the Cretaceous Ocean Anoxic Event 2 across the Cenomanian-Turonian boundary. Using a combination of both bottom-dwelling benthic foraminifera assemblages and the elemental composition of host sediments, they propose at least two short-lived re-oxygenation events during the black-shale 'Fischschiefer' interval, recovered in a core from Wunstorf in northern Germany. During these re-oxygenation events, sediments become repopulated with benthic foraminifera, the diversity of taxa increases and the concentration of elemental sulphur - a marker for oxygen depletion - declines. This work adds to growing evidence for more variable levels of bottom-water oxygenation, including the potential for short-lived coolingdriven intervals of ocean ventilation, during the mid-Cretaceous ocean anoxic events.

The final paper in this set moves into the Cenozoic and concentrates on a relatively long, multi-million-year record of Eocene coccolithophore assemblages from the central southern Tethys (Weinbaum-Hefetz \& Benjamini, 2011). Spanning the Early Eocene Climatic Optimum (EECO) and the subsequent trend of long-term high-latitude/deep-water cooling, this provides an interesting pattern of calcareous nannofossil assemblage changes across the interval of near-peak Cenozoic diversity. Although, at this stage, without corresponding geochemical palaeoceanographic proxy data, Weinbaum-Hefetz \& Benjamnini trace a number of interesting shifts in the dominance and diversity of major nannofossil genera, notably changes in the dominant Eocene rhabdolith genus, Blackites, and in the ratio of Coccolithus-type to Reticulofenestra-type placoliths.
Similar trends have been noted elsewhere, and further investigation of both these patterns in nannofossil assemblages and detailed palaeoceanographic work on the Eocene formations of Israel are highly desirable.

The range of these papers and the issues of global change they seek to address - from deep-ocean oxygenation, to Palaeozoic climate and biogeography, terrestrial plant community change and surface ocean phytoplankton dynamics - illustrate the continued great potential of micropalaeontological research in contributing to global change science. Perhaps micropalaeontologists are, by upbringing, interdisciplinary and this is one of their main strengths. We should continue to work closely with geochemists, palaeoceanographers, climate modellers and their like for the mutual interpretation of the geological record of environmental change. The IPC3 meeting was also an excellent reminder that we are also palaeontologists, and palaeontologists who are responsible for the development and interpretation of the most stratigraphically and taxonomically complete fossil records available. It is this interaction between many sciences that makes our discipline so fascinating and, if utilized to the full, will ensure its continued relevance to the wider community.

Finally a number of expressions of gratitude; first of all thanks to all who contributed to the great success of the TMS-sponsored IPC3 sessions: my fellow symposium convenors, Jeremy Young, Paul Bown, Daniela Schmidt and Taniel Danelian, all of those who attended and presented their research in these sessions and the IPC3 organizing committee. Second, thanks to the authors of the papers contained in this themed set, I have greatly appreciated reading your research and hope that others will as well. Third, I must record a heart-felt thank you to the many reviewers who contributed excellent and detailed comments on all of these papers, greatly assisting the task of editor and providing new insights to many of the authors. Finally, I would like to thank the journal editor-in-chief, Alan Lord, for including this thematic set and for his great editorial skills and judgement, and Sarah Gibbs of the Geological Society for smoothing the path of manuscript production.

\section{REFERENCES}

Friedrich, O., Voigt, S., Kuhnt, T. \& Koch, M. 2011. Repeated bottom-water oxygenation during OAE 2: timing and duration of short-lived benthic foraminiferal repopulation events (Wunstorf, northern Germany). Journal of Micropalaeontology 30, 119-128.

Mander, L. 2011. Taxonomic resolution of the Triassic-Jurassic sporomorph record in East Greenland. Journal of Micropalaeontology 30, $107-118$.

Weinbaum-Hefetz, M. \& Benjamini, C. 2011. Calcareous nannofossil assemblage changes from early to middle Eocene in the Levant margin of the Tethys, central Israel. Journal of Micropalaeontology 30, 129-139.

Žigaitè, Ž., Karatajūtè-Talimaa, V. \& Blieck, A. 2011. Vertebrate microremains from the Lower Silurian of Siberia and Central Asia: palaeobiodiversity and palaeobiogeography. Journal of Micropalaeontology 30, $97-106$.

Tom Dunkley Jones

Department of Earth Science and Engineering, Imperial College, London SW7 2AZ, UK (e-mail: t.dunkley-jones@imperial.ac.uk) 